\title{
Operational aspect of the policy coordination for financial stability: role of Jeffreys-Lindley's paradox in operations research
}

\author{
Muhammad Ali Nasir $^{1}$ (D) Alaa M. Soliman ${ }^{1} \cdot$ Muhammad Shahbaz $^{2,3,4}$ \\ Published online: 21 May 2020 \\ (c) The Author(s) 2020
}

\begin{abstract}
This study analyses the implications of Jeffery-Lindley's paradox and Global Financial Crisis (GFC) for the operational aspect of macroeconomic policy coordination for financial stability. Using a Bayesian Vector Auto-regressive model and data from Jan 1985 to June 2016, our key findings suggest that the claim of macroeconomic policy interaction, interdependence and significance of coordinated policy operations for the financial stability holds its ground. The argument in the support for policy coordination for financial stability was found to be robust against the Jeffreys-Lindley's paradox and in the Post-GFC era. A profound practical, operational and philosophical implication of this study is the positive aspects of Jeffreys-Lindley's paradox and the possibility of employing the Frequentist and Bayesian estimation techniques as complementing rather competing frameworks.
\end{abstract}

Keywords Macroeconomic policy operation - Financial markets · Macroeconomic policy interaction · Bayesian estimation · Jeffreys-Lindley's paradox $\cdot$ Operations research

JEL Classification E44 · G12 · E61

\section{Introduction}

Economic policies have profound operational implications and are important tools for any government to achieve its socio-economic objectives and financial obligations. In light of contemporary wisdom and consensus on the role and effectiveness of the policies, one may

\section{Muhammad Ali Nasir \\ m.a.nasir@leedsbeckett.ac.uk \\ Muhammad Shahbaz \\ muhdshahbaz77@gmail.com}

1 School of Accounting, Finance and Economics, Faculty of Business \& Law, Leeds Beckett University, The Rose Bowl, Portland Crescent, Leeds LS1 3HB, UK

2 Beijing Institute of Technology, Beijing, China

3 Department of Land Economy, University of Cambridge, Cambridge, UK

4 Department of Economics, COMSATS University of Islamabad, Lahore Campus, Lahore, Pakistan 
not be in a position of absolute confidence to deny the importance of macroeconomic policies, neither for the real economy nor for the financial sector (see Bredin et al. 2007; Ardagna 2009; Arnold and Vrugt 2010). An important point to make upfront is that to achieve the desired objectives by using macroeconomic policies i.e. either monetary policy, fiscal policy or maybe a combination of both, experts in the field rely on some sort of a framework which could lead to recommend or prescribe an optimal policy response. Putting it simply, a method of analysis could help in deciding what policy actions should be taken and with how much intensity: for instance, should we use a contractionary or expansionary macroeconomic policy, and in so doing, what should be the extent of policy shock. The operational question which may arise here which also provides the rationale for this study is 'what are the limitations associated with relying on a particular framework of analysis? Keeping that in perspective, the Bayesian (based on Bayes' theorem) and Frequentist (based on Gauss-Markov theorem) approaches to estimation and causal analysis varies from each other in various contexts. For instance, the Frequentist approach is deterministic whereas the Bayesian approach is stochastic in nature. Nevertheless, these differences in empirical approaches may have profound operational implications as they may show different impacts of macroeconomic policies. In this respect, Robert (2013) cautioned that each estimation approach may lead to a different conclusion and one can end up in a situation called Jeffreys-Lindley's Paradox.

The issue of divergence between the Bayesian and Frequentist approach was initially discussed by Jeffreys (1939) and later seminal work by Lindley (1957) described it as a Paradox. Despite its theoretical and scholarly relevance, such an issue of divergence between different frameworks of analysis could also have profound policy implications for a practitioner. There are some studies which have discussed the subject paradox and suggested some remedies (see Spanos 2013; Villa and Walker 2017), however, specifically, this study adds to the existing evidence ${ }^{1}$ by analysing the operational aspect of policy coordination for the financial stability in the light of Jeffreys-Lindley's Paradox and Global Financial Crises. The first research questions the subject study focusing on is how the monetary and fiscal policy impact the financial markets? Secondly, the study investigates whether there is interaction between monetary and fiscal policies and if the notion of policy coordination for financial stability holds in a Bayesian Framework? The third research question we focus on is whether the impact macroeconomic policies on the financial sector is still significant in the post GFC period. Lastly, the subject study investigates how the policy interaction materialises in the Post-GFC era? The reason to consider the implications of the GFC is that the empirical evidence showed a shift in the association between the USA stock market and monetary policy after the GFC (Kontonikas et al. 2013) as well as a winder shift in the responsiveness of global financial markets (Nasir and Du 2018). Thus, an analysis of the operational role of macroeconomic policies and resulting policy choices might be influenced by not only the choice of the empirical approach employed to perform the policy analysis but the GFC may also affect the association between macroeconomic policies and the financial sector. ${ }^{2}$

This study also considers the symmetry of stock and bond market response to macroeconomic policy operations; the logical reason for this is that when the economic policy

\footnotetext{
${ }^{1}$ This study is capitalising on existing evidence and particularly on the work by Nasir and Soliman (2014) which employed a VAR framework to analyse the implications of macroeconomic policy coordination for the financial sector.

2 The particular aspects of the financial sector that this study is considering are the stock (equity) and bond (sovereign debt) markets. The rationale for this choice is due to them being good indicator of future and present financial outlook (Broome and Morley 2004) and also wealth effects created by the stock and bond markets which feed into the real economy through consumption and investment spending (for detailed discussion, see e.g. Malikane and Semmler 2008; Funke et al. 2010; Airaudo et al. 2011; Nasir et al 2015).
} 
operations are targeting a particular market, for example, the bond market, it would be cogent to account for the response of the equity market. The reason for this choice becomes even more obvious if we refer to earlier studies which emphasised the importance of both equity and debt markets. The economic policy operations leading to the positive performance of a particular financial market and consequent wealth effects could unintendedly offset by the negative impact of the same policy operation on the other financial markets. There are a very limited number of studies which focused on the symmetry of equity and debt market reaction to macroeconomic policy operations and the results are contrasting and inconclusive. For instance, Gulley and Sultan (2003) reported that in response to the expansionary monetary operations both stock and bond markets showed a positive response and vice versa. In another study by Tavares and Valkanov (2003), it was reported that the contractionary fiscal policy operations negatively affect both markets. Hence, a homogeneous response of both markets was reported by Gulley and Sultan (2003) on monetary policy operation and by Tavares and Valkanov (2003) on fiscal policy operations. These pioneer studies on the symmetry of financial markets (equity and bonds) focused only on either fiscal or monetary policy operations and did not focus on their interaction and joint operations, though it is important to consider them both together (Neck and Karbuz 1995; Aarle et al. 2002; Porqueras and Alva 2010; Sims 2011a, b; Flotho 2018). Nonetheless, it is also important to acknowledge that some studies, for instance, Paulson (2013) reported that the relationship between the stock and bond markets in the US has been dynamic and varied from positive to negative. Concomitantly, this study also accounts for the symmetry of financial markets' responses. To achieve our objectives, we employ a Bayesian Vector Auto-regressive (BVAR) model on the data from Jan 1985 to June 2016. The key findings of our analysis suggest that the stock and bond market are influenced by each other as well as macroeconomic policy interactions. The responsiveness of the stock and bond markets have been increased Post-GFC which can be associated with the increase in the elasticity of substitution or increase in the sensitivity of investor's portfolio adjustment in the Post-GFC world. Hence, the aspect of policy interaction and coordination is vital even in the Post-GFC era. The argument on the notion of policy coordination for financial stability was found to be robust against the Jeffreys-Lindley's paradox. While the debate on the paradox may remain valid in theoretical and philosophical circles, on the practical grounds, there is a possibility of employing Frequentist and Bayesian estimation techniques as complementing rather competing frameworks.

The paper proceeds as follows: Sect. 2 will provide a brief discussion on existing evidence on the aspect of Policy coordination, implications of Jeffreys-Lindley's Paradox and Global Financial Crises. Section 3 briefly describes the empirical framework and sets out the underlying Bayesian theorem which provides the basis for the estimation approach. Section 4 will present the results of analysis and empirical findings which will lead to conclude the argument in Sect. 5.

\section{Coordinated policy operations, Jeffreys-Lindley's paradox and GFC}

Coordination in the policy operations is considered to be vital when the macroeconomic policies complement or contradict each other in the achievement of objectives which provide the basis for their formulation at the first place. In this aspect, Sargent and Wallace (1981) in their seminal work which laid the foundation of the fiscal theory of price level, urged on the coordinated monetary and fiscal policy efforts to achieve the objective of price stability. In later studies, Neck and Karbuz (1995), Dixit and Lambertini (2001, 2003) also emphasised 
the importance of policy coordination. Perhaps, the argument will not be complete unless we acknowledge the metaphor by Leeper that "Analysing one policy is like dancing a tango solo: it's a lot easier, but it is incomplete and ultimately unfulfilling" (1993, p. 3). In the same spirit, Zubairy (2009) and Davig and Leeper (2011) argue that coordinated policy actions are important as the fiscal and monetary policies may counteract each other. However, studies that focused on the coordination of monetary and fiscal policy and its effects on the real economy (output growth, inflation and employment), have often documented contrasting accounts. For instance, in a study on the European Monetary Union, Aarle et al. (2002) showed that the cooperation is often efficient for the fiscal players, though it may not always be optimal for monetary authority (European Central Bank). In a rather recent study on the interaction of fiscal and monetary policy in a monetary union under the zero lower bound (ZLB) constraint, Flotho (2018) found that under the ZLB constraint the fiscal policy plays an active role in stabilizing the economy. Furthermore, that the affective fiscal policy management can reduce the length of ZLB constraint. Interestingly, it was also argued that coordination is not always preferable. The study by Aarle et al. (2002), Flotho (2018) did use a calibrated theoretical model without any empirical real-world data which implies that with various limitations (e.g. small-scale, two-country model with symmetric assumptions) the model and inferences may not hold their ground in the face of real-world data. On the question of fiscal and monetary coordination in the EMU, the recent proposal by Dosi et al. (2019) does supports the notion of coordination by taking a route to debt mutualisation and fiscal union. In the evidence form other economies, for instance, in the study on Austria by Neck (1999) it was shown that the fiscal authority was more influential for macroeconomic targets than monetary policy. On the contrary, Saulo et al. (2013), analysed the monetary and fiscal policy coordination in a game-theoretical setting. Their numerical excise employing Brazilian data showed that a Stackelberg approach with monetary policy leading and fiscal policy following is the best way to coordinate. While these contrasting results reported by various studies are intriguing, another challenge which one may face in coordinated policy operations is that we may face a trade-off when the underlying objectives are more than one. For instance, putting it simply, in the subject case, a policy combination that is positively affecting one market, for instance, the stock market might have negative effects on the bonds and vice versa. Concomitantly, it is also vital to account for the symmetry of financial markets reaction to coordinated policy actions, an aspect which the subject study is intended to consider. Nevertheless, their policy prescription is still prone to criticism on the choice of the estimation techniques and the symmetry of the response of financial markets to policy decisions.

To reiterate, the methodology plays an important role in assessing the impact of policy as well as the coordinated policy operations. The monetary and fiscal authorities rely on various empirical and theoretical frameworks prescribe an optimal policy action. Therefore, method of analysis could help in deciding what policy actions should be taken and with how much intensity: for instance, should we use a contractionary or expansionary macroeconomic policy, and if so, what should be the extent of policy shock. The operational question which arises and provides the rationale for this study is "what are the limitations associated with relying on a particular analytical framework, especially when it comes to influencing the financial sector?' The Bayesian (based on Bayes' theorem) is stochastic whereas the Frequentist (based on Gauss-Markov theorem) is rather a deterministic approach. These differences in empirical approaches may have profound operational implications as they may show different impacts of macroeconomic policies. In this respect, Robert (2013) cautioned that each estimation approach may lead to a different conclusion and one can end up in a situation called the Jeffreys-Lindley's Paradox. The issue of divergence between the Bayesian and Frequentist approaches was initially discussed by Jeffreys (1939) and later described by Lindley (1957) 
in his seminal work as a Paradox. ${ }^{3}$ As Lindley (1957) argued "the theory does not justify the practice of keeping the significance level fixed" Furthermore, "some computations by Prof. Pearson in the discussion to that paper emphasized how the significance level would have to change with the sample size, if the losses and prior probabilities were kept fixed" (Naaman 2016, p. 1528). On the suggestion to deal with this Paradox, Naaman (2016) proposed that "as the sample size grows, the probability of a type I error will become arbitrarily small by allowing the significance level to decrease with the number of observations in the study". Similarly, Sprenger (2013) suggested that an alternative approach could be the Bayesian Reference Criterion (BRC), with reasons that it focuses on predictive performance and likely replication of the effect. Therefore, arguably, it conveniently and convincingly addresses the Lindley's Paradox. While Spanos (2013) argued that it is fallacious that irrespective of $n$; the rejection of null is interpreted as evidence of a specific alternative. It is a prima facie example of the fallacy of rejection. Furthermore, both the Bayesian and Frequentist approaches are potentially susceptible to the fallacy of acceptance. On the Frequentist part Spanos (2013) showed that testing the severity evaluation circumvents both fallacies, however, this solution is not available in other approaches. Contrarily, Robert (2013) despite acknowledging the contribution on the debate by Spanos (2013) disagreed on the idea of severity evaluation as it fails to be a convincing alternative to and criticism of the existing branches of statistical hypothesis testing. In the most recent study on the subject, Villa and Walker (2017) argued that the philosophical argument shall be regarded as irrelevant and to deal with the paradox, one shall use simple mathematics.

The subject treatise is not only intended to investigate the implications of alternative empirical frameworks or focus on the symmetry of stock and bonds markets to policy operations but also to consider the implications of GFC for the aspect of policy operations. Concomitantly, we are particularly interested in investigating if and how the significance of macroeconomic policy operations for the financial sector has been changed over the Global Financial Crises of 2008-2009. ${ }^{4}$ The GFC had vital global implications and the contingent affected almost every aspect of the global financial market, the intriguing question is whether economic policy operations and their association with financial markets in the Post-GFC world have been changed. The existing evidence on the subject suggests that the financial markets have shown a change in the behaviour after major events of the crisis. For example, focusing on the financial crisis of 1987 and 1999 Wong et al. (2006) reported that the relationship between stock markets and macroeconomic variables employed in their study has become weaker post crises. It led them to argue that the financial markets have become efficient. Their findings and reasoning imply that a crisis like the GFC of 2008 shall increase the efficiency or to say least, shall lead to change in its reaction function? Or what implications could it have for the optimal policy combination for the financial markets? In specific to the GFC, Kontonikas et al. (2013) reported a change in the reaction function of stock market to monetary policy operations in the US as the impact of expansionary monetary operation changed from positive to neutral in the Post GFC period. Similarly, in another study on US financial (banking) sector, Berger and Bouwman (2012) reported that the impact of monetary policy operations became milder during and after the Dotcom bubble. While on stock markets in Australia, EU, New Zealand and UK, Wang and Mayes (2012) reported that heterogeneities in their reaction to surprise monetary policy operations between pre and post-crisis periods. In a contemporary study by Fischbacher et al. (2012) on the Swiss stock and bond markets also reported a shift in the reaction function to the financial markets to monetary policy operations after the

\footnotetext{
3 With this association it is called Jeffreys-Lindley's Paradox.

4 The study by Nasir and Soliman (2014) was limited to the Pre Global Financial Crisis (2008) period.
} 
financial crisis. Most recently, Nasir and Du (2018) reported a shift in the association among the international financial markets since GFC. Concomitantly, these studies and presented empirical evidence clearly suggest that the financial crisis such as GFC leads to a shift in the response of financial markets to policy operations. It also provides the rationale to this study by posing the questions that how financial markets behaviour to fiscal and monetary policy operations might have changed due to the GFC? Concomitantly, it makes a case to revisit the aspect of policy coordination for financial stability in the Post-GFC world as we have ample evidence to support the shift in the response of the stock market to monetary policy alone, which is one reason of this endeavour.

\section{Empirical framework}

The employed Bayesian-Vector Autoregressive (BVAR) model has certain advantages over the traditional VAR model for the analysis of large data sets (see Banbura et al. 2010). Furthermore, the BVAR also differs from the traditional VAR model as it treats the parameters as random variables and prior probabilities are assigned to them. For this reason, the BVAR model is a good statistical method against the issue of over-parametrisation (Koop and Korobilis 2010). The Bayesian Vector Autoregressive (BVAR) model adopts the following form of simultaneous equations:

$$
\begin{aligned}
& \ln \text { Stock }_{i, t}=\alpha_{10}+\sum_{i=1}^{n} \beta_{1} \ln \text { Stock }_{, t-i}+\sum_{i=1}^{n} \gamma_{1} \text { Bond }_{t-i} \\
& +\sum_{i=1}^{n} \theta_{1} \text { Monetary }_{t-i}+\sum_{i=1}^{n} \delta_{1} \text { Fiscal }_{, t-i}+\varepsilon_{1 i, t} \\
& \text { Bond }_{i, t}=\alpha_{20}+\sum_{i=1}^{n} \beta_{2} \ln \text { Stock }_{, t-i}+\sum_{i=1}^{n} \gamma_{2} \text { Bond }_{i, t-i} \\
& +\sum_{i=1}^{n} \theta_{2} \text { Monetary }, t-i_{i=1}^{n}+\sum_{2} \text { Fiscal }_{, t-i}+\varepsilon_{2 i, t} \\
& \text { Monetary }_{i, t}=\alpha_{30}+\sum_{i=1}^{n} \beta_{3} \ln \text { Stock }_{, t-i}+\sum_{i=1}^{n} \gamma_{3} \text { Bond }_{i, t-i} \\
& +\sum_{i=1}^{n} \theta_{3} \text { Monetary }_{t-i}+\sum_{i=1}^{n} \delta_{3} \text { Fiscal }_{, t-i}+\varepsilon_{3 i, t} \\
& \text { Fiscal }_{, t,}=\alpha_{40}+\sum_{i=1}^{n} \beta_{4} \ln \text { Stock }_{t-i}+\sum_{i=1}^{n} \gamma_{4} \text { Bond }_{t-i} \\
& +\sum_{i=1}^{n} \theta_{4} \text { Monetary }_{t-i}+\sum_{i=1}^{n} \delta_{4} \text { Fiscal }_{t-i}+\varepsilon_{1 i, t} \\
& \varepsilon_{t}^{\sim} N(0, \sigma 2),
\end{aligned}
$$

where the Stock ${ }_{t}$, Bonds $s_{t}$, Monetary, and Fiscal, , are $(\mathrm{n} \times 1)$ vectors of endogenous variables, $\beta_{i}$ are $(\mathrm{n} \times \mathrm{n})$ coefficient matrixes and $\varepsilon$ is the white noise assumptions I.I.D. i.e. et $\tilde{N}(0, \sigma 2)$.

The empirical results obtained from the estimation of the BVAR model will provide us with some insight regarding the association between policy interaction and financial markets. 
Based on the research questions posed earlier (introduction section), we will accept the null hypothesis of no significant impact $\left(H_{0}: b_{i}=0\right)$ or reject them in favour of alternative hypothesis $\left(H_{1}: b_{i} \neq 0\right){ }^{5}$ however, there is an inherent limitation as, over different time periods, the financial markets may respond differently to the dynamics policy operations. Estimation of parameters within the BVAR model may yield us a wide range of coefficients for each variable which may also differ in size, sign, and statistical significance. This may add to the difficulty of drawing any inference on the overall responsiveness of the financial markets to policy operations. Therefore, as suggested by Canova (2007) an IRF analysis allows us to address this issue. Concomitantly, after the estimation of the model, this research uses Impulse Response Function (IRF) analysis where a policy shock is used to analyse the impacts on the response variables which may persist over several periods. Given the fact that each monetary and/or fiscal policy operation can be expansionary or contractionary, we have the possibility of four combinations in join policy operation. In terms of optimality, a joint policy operation which leads to positive impact on equity and bond markets is perceived to be desirable as through the creation of wealth effects it also contributes to financial and economic stability.

\subsection{Bayesian estimation and Bayes theorem}

Contrary to the earlier studies on policy interaction and join operations (e.g. Nasir and Soliman (2014) in this study, we estimate the VAR model by employing the Bayesian approach. This is a full information approach and one of its novelty is that it fits the model to the data with all its accompanying variation (see Zubairy 2009). The Bayesian approach is also superior to the models which ware built on the dogmatic prior to structural parameters (Milani and Poirier (2007). Nonetheless, the Bayesian approach provides a formwork for evaluation even to the models with weak specification and Maximum Likelihood asymptotically converges to Bayesian estimation for the large samples ((Merola (2009). The Bayesian estimation is based on the Bayes' Theorem which can be denoted as follows: assuming that $\theta$ is the Parameter of interest, $\mathrm{p}(\theta)$ represents the prior density of the parameter vector $\theta$,

$$
P(\theta \mid y T)=\frac{\mathrm{L}(y T \mid \theta) P(\theta)}{\theta_{\Theta} L(\mathrm{yT} \mid \theta) P(\theta) d(\theta)} \propto \mathrm{L}(\mathrm{y} \mathrm{T} \mid \theta) P(\theta)
$$

$\mathrm{L}(y \mid \theta)$ is the likelihood of the sample y with T observations whereas $\int_{\Theta} \mathrm{L}(\mathrm{y} \mid \theta) \mathrm{P}(\theta) \mathrm{d}(\theta)$ is the marginal density of the sample and $P(\theta \mid y)$ is posterior density.

In principle, we start from a prior value or belief on the parameter of interest $\theta$, and as we bring the model to data, we modify our belief or revise probabilities. Application of this approach in this section with said benefits would also give us insight into the sturdiness and validity of joint policy operations.

\subsection{Prior's selection}

Formulation of the prior distribution of the parameters which are to be based upon information that reflects researchers' beliefs is a core feature of Bayesian approaches. The prior information incorporated in the Bayesian framework compliment drawing of inferences about the true values for the parameters of interest. The seminal work on the Litterman or Minnesota prior was carried out at the Federal Reserve Bank of Minneapolis and at the University of

5 where $b_{i}$ are parameters of association i.e. $\beta \gamma, \theta$ and $\delta$. 
Minnesota and (see Litterman 1984; Doan et al. 1984). For this reason, priors are referred to as the "Litterman prior" or the "Minnesota prior". These priors are based on an assumption that $\sum_{\varepsilon}$ is known; replacing $\sum_{\varepsilon}$ with its estimate $\sum \wedge \varepsilon$. The benefits of assumption include simplifications in prior elicitation as well as computation of the posterior. We have three choices of an estimator of $\sum_{\varepsilon}$. which include Univariate AR, Full VAR and Diagonal VAR ${ }^{6}$

Since $\sum_{\varepsilon}$ is replaced by $\sum^{\wedge} \varepsilon$, we need only to specify a prior for the VAR coefficient $\theta$ The Littermanprior assumes that the prior of $\theta$ is

$$
\theta \sim N\left(\theta_{0}, V_{0}\right)
$$

$\theta_{0}=\mu_{1} i_{m p}$ where the hyper-parameter $\mu_{1}=0$, which indicates and non-zero prior covariance $V_{0} \neq 0$ and a zero-mean model. While the choice of zero mean could lessen the risk of over-fitting, theoretically any value for $\mu_{1}$ is possible.

In Minnesota/Litterman prior for the covariance $V_{0}$, the explanatory variables in the VAR in any equation can be divided into own lags of the dependent variable, lags of the other dependent variables, and finally any exogenous variables, including the constant term. The elements of $V_{0}$ corresponding to exogenous variables are set to infinity (i.e. no information about the exogenous variables is contained within the prior).

The remainder of $V_{0}$ is then a diagonal matrix with its diagonal elements $v_{i j}^{l}$ for $l=1, \ldots p$

$$
v_{i j}^{l}= \begin{cases}\left(\frac{\lambda_{1}}{l^{\lambda} 8}\right)^{2} & \text { for }(i=j) \\ \left(\frac{\lambda_{1} \lambda_{2} \sigma_{i}}{l^{\lambda} 8 \sigma_{j}}\right)^{2} & \text { for }(i \neq j)\end{cases}
$$

where $\sigma_{i}^{2}$ is the $i$ th diagonal element of $\sum_{\varepsilon}$. This prior setting simplifies the complicated choice of specifying all the elements of $V_{0}$ down to choosing three scalars $\lambda_{1}, \lambda_{2}$, and $\lambda_{3}$. The first two scalars $\lambda_{1}$ and $\lambda_{2}$ are overall tightness and relative cross-variable weight, respectively. $\lambda_{3}$ Captures the lag decay that, as lag length increases, coefficients are increasingly shrunk towards zero. The changes in these hyper-parameter scalar values may lead to smaller (or larger) variances of coefficients, which is called tightening (or loosening) the prior. The exact choice of values for these three scalars depends on the empirical application so that one can make trials with different values for themselves (see Litterman (1984) for a detailed discussion).

\subsection{Data}

The monthly data from January 1985 to Aug $2008^{7}$ and January 2009 to June 2016 (to analyse the implication of the GFC) is employed. The division of the time period into two sub-periods

6

- Univariate $A R \sum^{\wedge} \varepsilon$ is restricted to be a diagonal matrix, where $\sigma_{i i}^{\wedge}$ the $(i, i)$ th element of $\sum^{\wedge} \varepsilon$, is the standard OLS estimate of the error variance calculated from an univariate AR regression using the $i$ th variable.

- Full VAR estimates a standard classical VAR and uses the covariance matrix from that estimation as the initial estimate of $\sum^{\wedge} \varepsilon$. This choice is not always feasible in cases where there are not enough observations to estimate the full VAR.

- Diagonal VAR $\sum{ }^{\wedge} \varepsilon$ is restricted to be a diagonal matrix (as in the univariate VAR estimator), however the diagonal elements of the matrix are calculated from the full classical VAR (i.e., the diagonal elements are equal to those in the full VAR method, and the non-diagonal elements are set equal to zero).

7 As used by Nasir and Soliman (2014) while using the simple VAR model. 
Table 1 ARCH test on stock and bonds markets

*AutoRegressive conditional hetroskadicity (Marquardt) test

\begin{tabular}{llll}
\hline Stock & & & $P$ value \\
\hline F-statistics & 1.746 & Prob.F (3.277) & 0.158 \\
Obs*R-squared & 5.216 & Prob. Chi square (3) & 0.157 \\
Bonds & & & \\
F-statistic & 1.980 & Prob. F (3.277) & 0.117 \\
Obs*R-squared & 5.898 & Prob. Chi square (3) & 0.117 \\
\hline
\end{tabular}

is due to the reason that, firstly, it will help to estimate the model for the same period as Nasir and Soliman (2014) but using a Bayesian VAR model and secondly the second sub-period is the Post-GFC period which will help us to understand the influence of the GFC on the aspect of policy coordination. The rationale of subsampling in similar scenarios is supported by Politis et al. (1999) and Wong et al. (2006).

The stock and bond data are monthly frequencies of daily averages; thus it is fairly highfrequency data. (Hautsch et al. 2011). To proxy the monetary policy operation, we used the Bank of England's official Bank Rate which is also the instrument used by the monetary authority. To represent the stance of fiscal policy (operations) we use the proxy of the Public Sector Net Cash/Borrowing Requirements as a percentage of national income (GDP). In terms of the fiscal stance, a fairly common convention is to either use debt or deficit to income (GDP) ratios, however, we chose the latter. It is a deficit to income ratio and measures activity over a period of time, concomitantly a better representation of fiscal stance (Muscatelli et al. (2004).

On the representation of financial markets, the real yield on UK Government bonds which are also called Gilts is used as a proxy for the response of Bonds market, monthly averages of real yield which is the inverse of bond prices is a good proxy for bond markets' response. The yield on bonds represents government borrowing cost and it also reflects returns on investment as well as reflects the level of confidence of market participants (See Campbell 1995). As a proxy for the stock market, monthly average values of the FTSE-100 index are used. Several studies (e.g. Funke et al. (2010) and Airaudo et al. (2011) examining stock market also used stock indexes as the proxy. Nonetheless, the chosen FTSE-100 represents the major companies which account for more than $80 \%$ of the total capitalization of the London Stock Exchange (L.S.E). Our sources of data are the Bank of England's database the Bankstates, the Office for National Statistics (ONS), FTSE Group, and Thomas Reuter's database the DataStream.

\section{Analysis and findings}

To start with, we conducted three tests on data series to gain insight into their statistical properties. Firstly, to check the persistence of volatility of financial markets we performed AutoRegressive Conditional Hetroskadicity $(\mathrm{ARCH})$ test which is effective in finding whether the previous period's innovations disproportionally influence the current period innovation. The results are in Table 1.

The results indicated the absence of ARCH effects $5 \%$ level of significance ( $p$ value $>0.05$ ) and null of no ARCH effect was not rejected. Secondly, we test for stationarity. We must acknowledge here that in their seminal work Sims (1990) and latter Fanchon and Wendel argued that in the Bayesian VAR stationarity is not a crucial requirement. However, we still 
Table 2 Augmented Dickey-Fuller unit root test

\begin{tabular}{|c|c|c|c|c|}
\hline & ADF test stat & $1 \%$ level & $5 \%$ level & $P$-value \\
\hline \multicolumn{5}{|c|}{ At level $I(0)$} \\
\hline Monetary & $(2.238)$ & (3.991) & $(3.425)$ & 0.466 \\
\hline Fiscal & (1.995) & (3.992) & (3.426) & 0.600 \\
\hline Stock & $(1.876)$ & (3.990) & $(3.425)$ & 0.664 \\
\hline Bond & $(0.402)$ & (3.453) & $(2.871)$ & 0.905 \\
\hline \multicolumn{5}{|c|}{ 1st differenced $I(1)$} \\
\hline Monetary & $(8.424)^{*}$ & (3.991) & (3.425) & 0.000 \\
\hline Fiscal & $(4.252)^{*}$ & (3.993) & (3.427) & 0.004 \\
\hline Stock & $(16.455)^{*}$ & (3.991) & (3.426) & 0.000 \\
\hline Bond & $(16.775)^{*}$ & (3.991) & (3.426) & 0.000 \\
\hline Residual & $(16.723)^{*}$ & (3.991) & (3.426) & 0.000 \\
\hline
\end{tabular}

conducted the ADF unit root to find if there is major explosive behaviour in the dataset. The results are presented in Table 2.

The results of the ADF unit root test showed that the data series were first differenced stationary i.e. $I$ (1) at a $1 \%$ level of statistical significance. This order of integration is not very surprising when dealing with financial and economic data. As said earlier it is not a fundamental assumption to satisfy under the Bayesian approach. Thirdly, we performed the Johansen co-integration test. The Cointegration testing in a Bayesian framework is also debatable as in their seminal work, Engle and Yoo (1987) postulated that it is not appropriate to use Bayesian estimation when we have co-integration as the standard prior imply a model that approaches the classical VAR model employed on a dataset which is differenced. Nonetheless, that also cautioned that the model could suffer from misspecification as the error correction term is not included. However, Fanchon and Wendel (1992) refuted this argued and argued that even in the case of non-stationarity and Cointegration the Bayesian framework is very useful (see Fanchon and Wendel 1992 for a detailed discussion). It is worth acknowledging argument by Warne (2006) that all the parameters of the co-integrated VAR are identified in the Johansen procedure. We performed the Johansen Co-integration test and the results presented in the Table 3 clearly suggest that there was no evidence of Cointegration as the null of no cointegration could not be rejected at $5 \%$ level of statistical significance.

Therefore, it is not required to include an error correction terms which is also not the case in Bayesian estimations and also fades the fear of issues raised by Engle and Yoo (1987).

Prior to the estimation of the model, it was required to decide on the number of lags to be included in the model. In order to do so, an optimal lag selection test is performed. ${ }^{8}$ The results showed that twelve lags were unanimously suggested as optimal by almost all of the information criteria, which were subsequently included in the model.

\subsection{Financial markets and policy interaction in Bayesian VAR}

The BVAR model (Eqs. 1-4) is employed and the estimation results are presented in Table 4.

The Diagonal VAR was used for initial residual covariance in which the diagonal elements of the matrix are calculated from the full classical VAR (i.e. the diagonal elements are equal to those in the full VAR method, and the non-diagonal elements are set equal to zero). The

8 To preserve the space the lag selection tests are not presented here and are available on request. 
Table 3 Johansen Co-integration test

MacKinnon et al. (1999) $P$-values

\begin{tabular}{|c|c|c|c|c|}
\hline $\begin{array}{l}\text { Hypothesized } \\
\text { no. of } \\
\text { CE(s) }\end{array}$ & Eigen value & $\begin{array}{l}\text { Trace } \\
\text { statistic }\end{array}$ & $\begin{array}{l}\text { Critical } \\
\text { value at } 5 \%\end{array}$ & $P$-values* \\
\hline \multicolumn{5}{|c|}{ Unrestricted co-integration rank test (Trace) } \\
\hline None & 0.052 & 26.666 & 47.856 & 0.866 \\
\hline At most 1 & 0.024 & 12.055 & 29.797 & 0.929 \\
\hline At most 2 & 0.018 & 5.204 & 15.495 & 0.786 \\
\hline At most 3 & 0 & 0.075 & 3.841 & 0.783 \\
\hline \multicolumn{5}{|c|}{ Unrestricted co-integration rank test (Maximum eigen value) } \\
\hline None & 0.052 & 14.611 & 27.584 & 0.778 \\
\hline At most 1 & 0.024 & 6.85 & 21.132 & 0.96 \\
\hline At most 2 & 0.018 & 5.128 & 14.265 & 0.725 \\
\hline At most 3 & 0 & 0.075 & 3.841 & 0.783 \\
\hline
\end{tabular}

hyperparameters with the values cited in Table 5 were used. The value of $\mathrm{R}^{2}$ is above $90 \%$, coupled with high F-statistics in most of the cases except fiscal policy which although still showed a significant yet lower values of $\mathrm{R}^{2}$ and F-stats implying fiscal policy operations as comparatively more exogenous in its formulation than other explanatory variables. An important finding was that the joint impact of all the explanatory variables was highly significant for stock and bond markets and the Exogeneity test results also supported the notion that the join monetary and fiscal operations were more effective. The results showed a few insignificant coefficients values, which is not too surprising in a model with multiple lagged explanatory variables (see Canova (2007) for a detailed discussion). While we have presented the empirical results obtained from our Bayesian Vector Autoregressive model in detail, they do not show an overall picture of the full analysis. To address this issue we performed an Impulse Response Function (IRF) analysis. It is worth mentioning here that there are is no reasoning for the confidence bands around the impulse line when using a Bayesian or VEC Model with error correction terms. This is because there is no uncertainty around the mean. As such, there are no logical grounds for confidence interval bands. The results are presented in Fig. 1.

The impulses generated from the Bayesian VAR show the loss of significance over longer lags and that the system is restoring to the mean. The main drawback of attempting to fully capture the dynamics of the system being modelled is that the longer the lags, the greater the number of parameters to be estimated and the fewer the degrees of freedom. Moreover, the presence of several lags of the same variable leads to parameter estimates not being statistically significant (See Pindyck and Rubinfeld 1997 and Pecican 2010). Concurrently, although the impact of the explanatory variable does not meet the statistical level of significance, yet it is still important as we are looking at this phenomenon in a broader context and making the best judgment based on the view of central tendency. ${ }^{9}$ The IRF showed that a shock to fiscal policy (fiscal expansionary operation) causes an increase in real yield on bond and an initial surge then drop and then long-term increase in stock prices, indicating a negative response from both bond and stock markets as prices of bond and stock fell. The general inference to draw is that the expansionary fiscal operations can negatively influence the equity and sovereign debt markets. The null hypothesis of no impact $\left(H_{0}: b_{i}=0\right)$ was

9 The seemingly minute isolation of financial markets still has vital implications for the economy (Carroll et al. (2011). Hence, the financial markets response to policy shocks are nontrivial. 


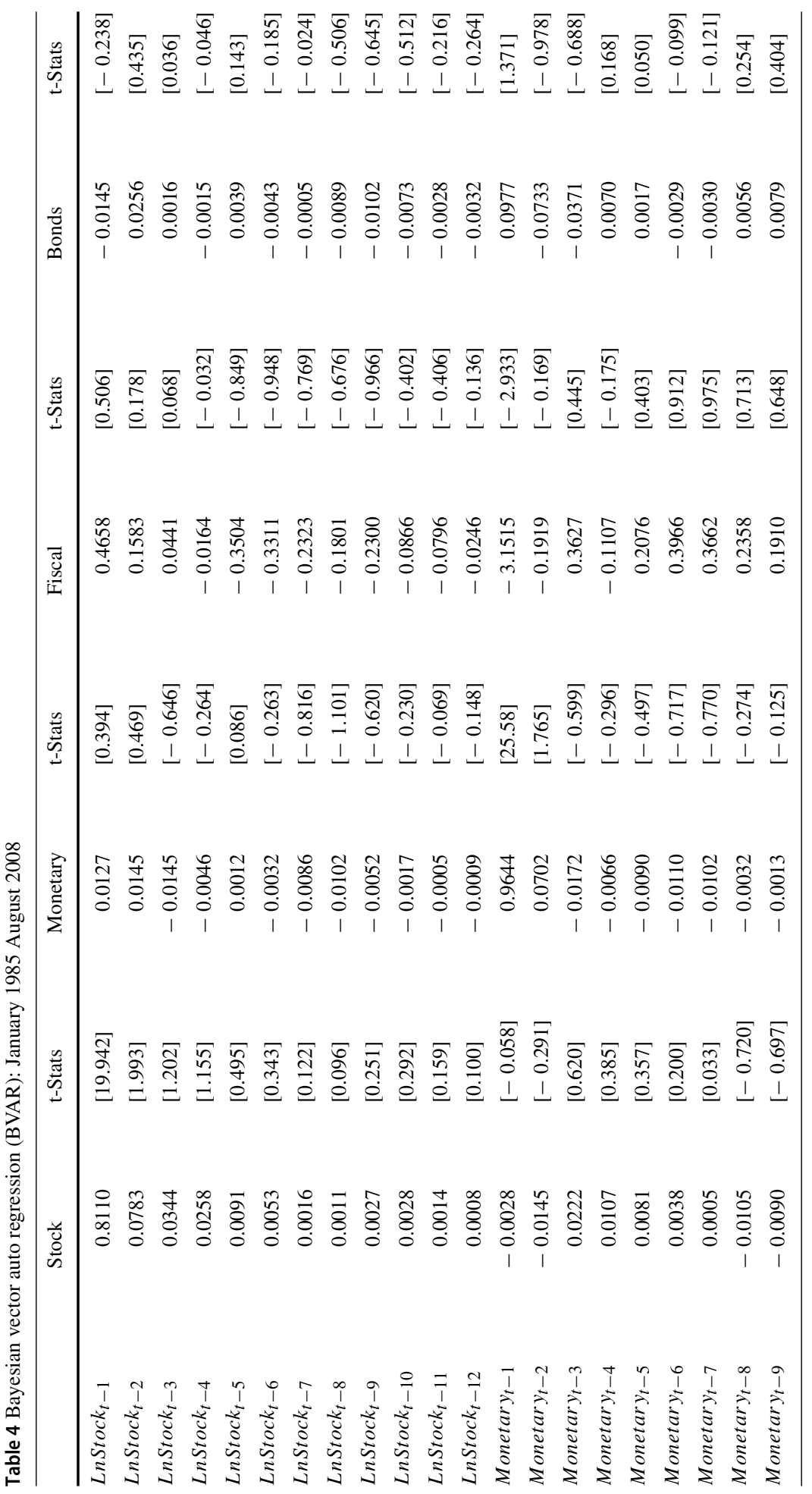




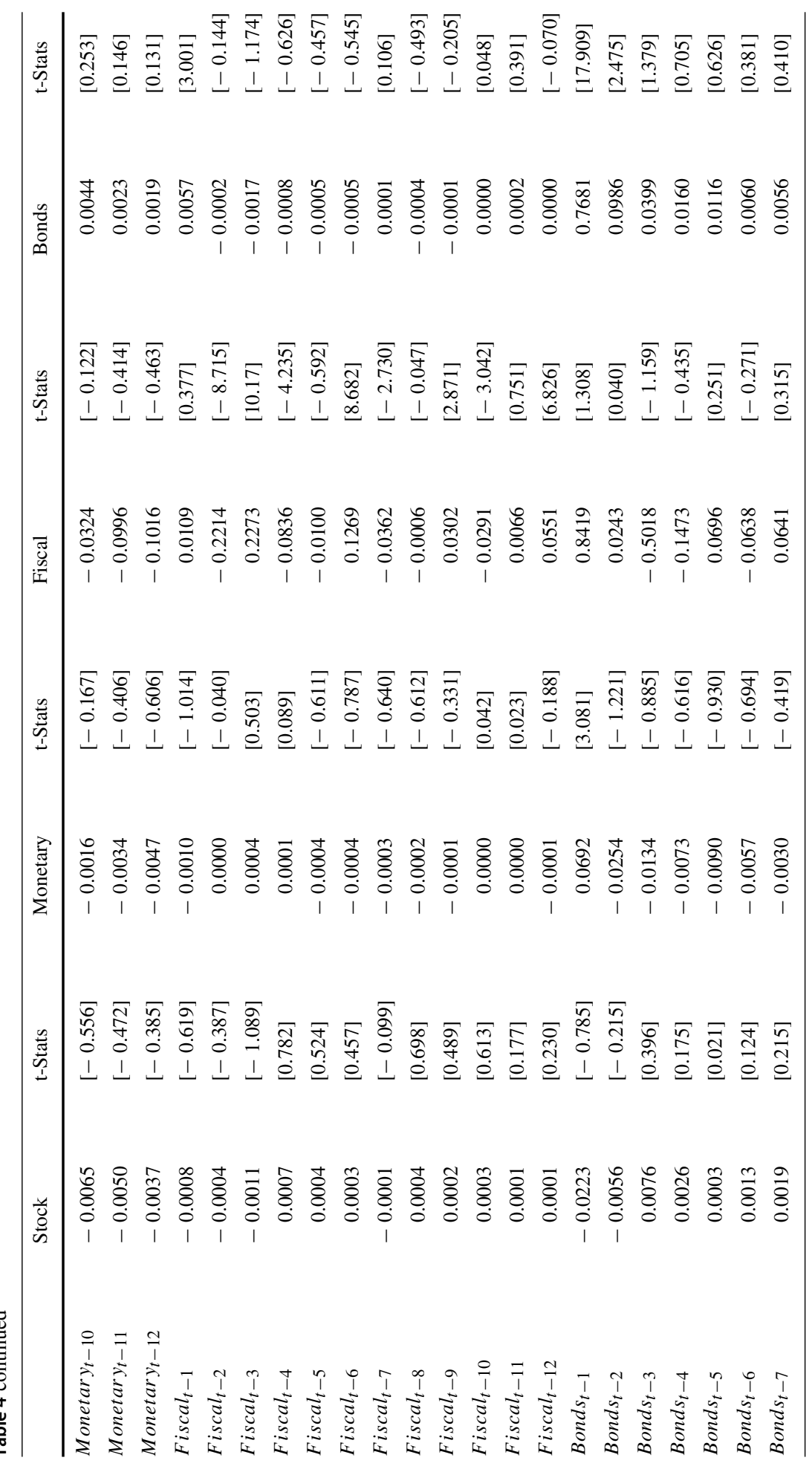




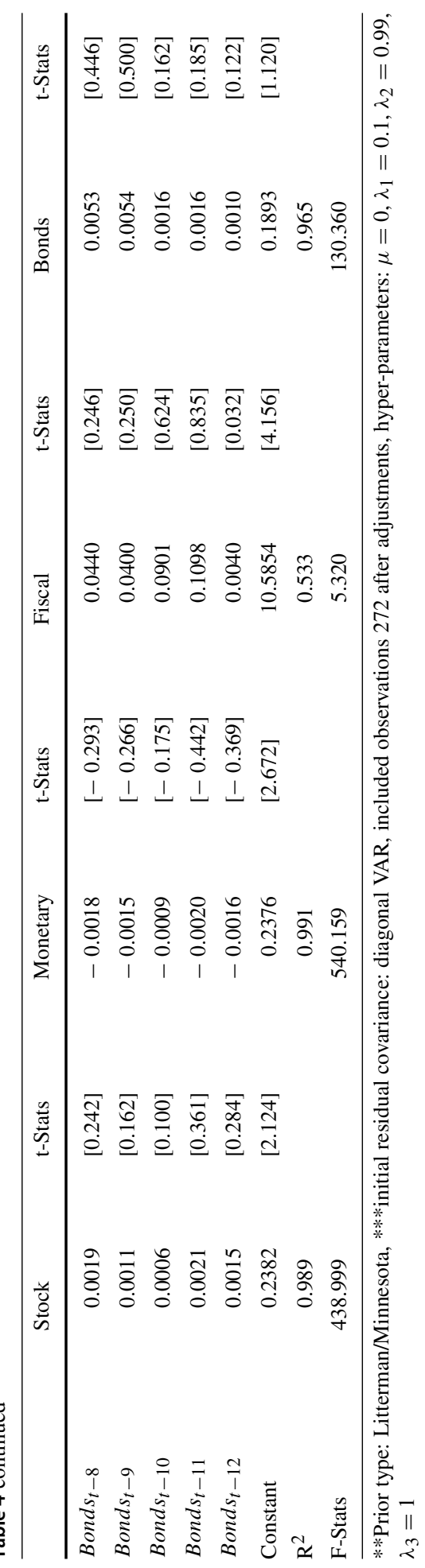

\section{照 Springer}




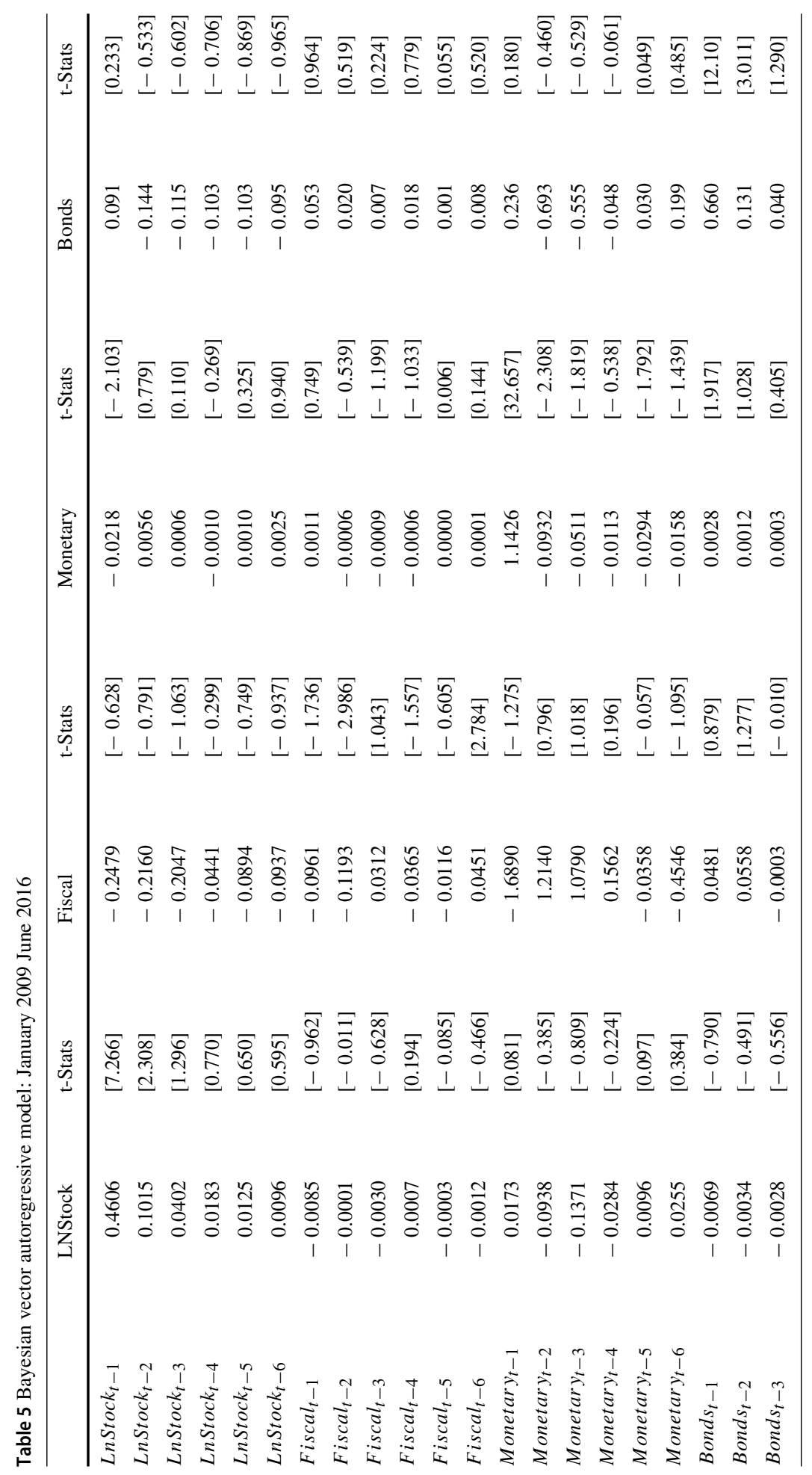




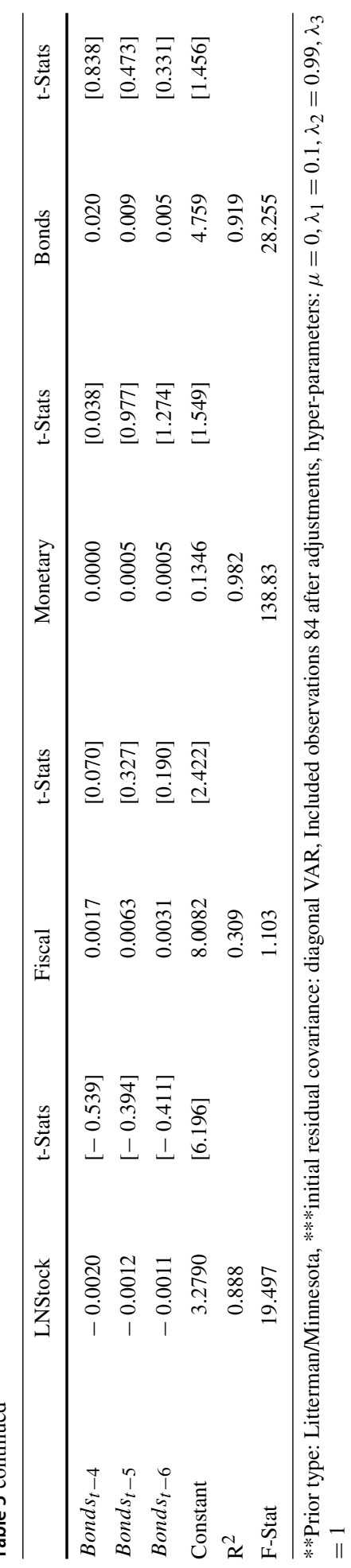

记 Springer 

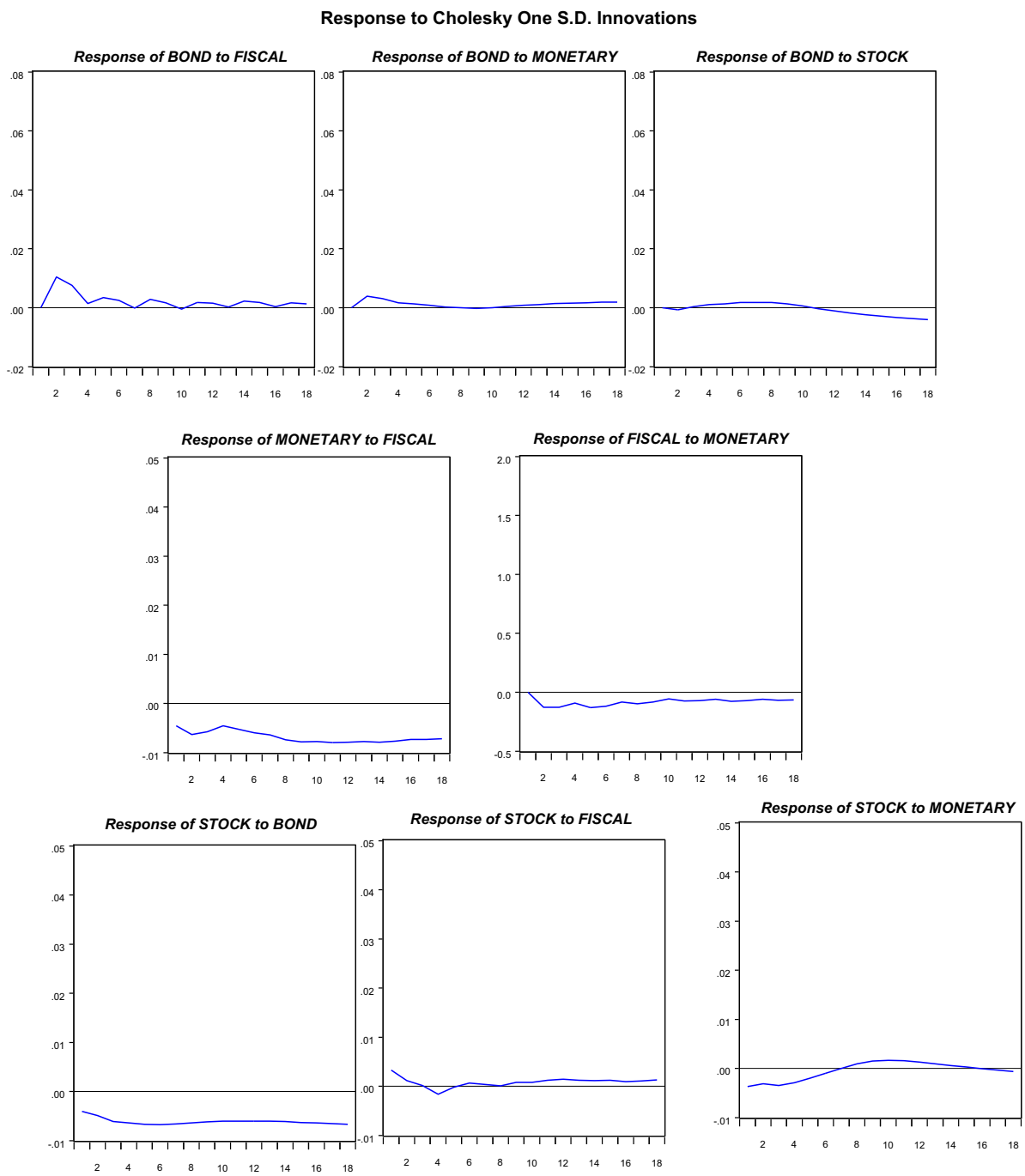

Fig. 1 Impulse response function (IRF). *There are no impulse response standard errors in Bayesian VAR model

rejected in favour alternative hypothesis of a none-zero impact $\left(H_{1}: b_{i} \neq 0\right)$. This finding was in line with the study by Tavares and Valkanov (2003) which shows that the expansionary fiscal policy operations negatively affect bond markets. On the other hand, the shock to monetary policy (expansionary or contractionary operations) received a similar response from stock and bond markets, although the response from the latter was more prolonged. Both markets show negative responses to contractionary monetary operations. Hence, once again the null hypothesis $\left(H_{0}: b_{i}=0\right)$ was rejected in favour alternative hypothesis $\left(H_{1}: b_{i} \neq 0\right)$ as we see how the monetary and fiscal policies significantly impact the financial markets. These findings are in line with the Gulley and Sultan (2003) study which show that bond and stock markets exhibit a positive response to an expansionary monetary stance. However, with compare to the study by Nasir and Soliman (2014) the stock and bond markets showed 
more persistent responses. The findings complement their study which used the VAR model and Frequentist approaches, as the direction of causality among variables in our study is not opposite, yet is more persistent and significant, which implies that the Bayesian VAR complement the findings by addressing the methodological limitations and giving us further insight. ${ }^{10}$

In terms of interdependence between the financial markets, the positive shock to stock market causes an initial increase in Bond's yield (decrease in prices) which later turns into a decrease in yield (increase in prices). Moreover, in response to increases in the Bond's yield, the stock market shows a consistently negative response which further confirms that the dynamics of the bond market are by far more significant for the stability of stock markets but not the other way around. The generalisation of results also implies that there exists a positive co-movement between the two markets. The findings were at odds with findings by Nasir and Soliman (2014), specifically in the long run, as the bond market shows a negative response to the stock market in their study. Hence, we can argue that the results presented in Fig. 1 are more intuitive in terms of long-term movements of both markets. It also implies that in longer periods, market participants may adjust their portfolio according to the performance of both the stock and bond markets. However, the markets are interdependent in terms of performance in long run. The results provide evidence of policy interactions and interdependence, for example, fiscal expansionary operations lead to consistently low bank rates (expansionary monetary stance). On the other hand, the increase in bank rates (monetary contraction) leads to fiscal consolidation (lower deficit to income or PSNBR/GDP ratios). The second null hypothesis of no interaction between policy or zero impact on each other $\left(H_{0}: b_{i}=0\right)$ was rejected in favour alternative hypothesis of interdependence or a non-zero impact $\left(H_{1}: b_{i} \neq 0\right)$ in a Bayesian Framework. These findings were in line with the study by Nasir and Soliman (2014) in terms of policy interaction but also support the arguments of Andrew et al. (2011) that the policies operational effects spill over to each other. The study by Andrew et al. (2011) was, however, focusing on the output and inflation whereas the subject study provides evidence of policy spillovers in the context of financial markets. In light of existing literature on the subject of monetary and fiscal policy interaction/coordination, the findings support the idea of policy coordinated policy operations advocated by Dixit and Lambertini (2003) for the real economy and Jansen et al. (2008) and lately the study by Nasir and Soliman (2014) for the financial markets (in Pre-GFC period). These findings further support the notion of policy coordination while using a Bayesian framework. Nevertheless, in the context of this study, along with the interdependence of macroeconomic policies symmetry of financial markets response to policy interaction is also an important aspect to take into account.

\subsection{Policy interaction post-global financial crisis}

In order to analyse the implications of the GFC for the aspect of policy interaction, in this section, we extend our inquiry into the Post- GFC period. As obvious, the under analysis variables are the same as in the previous section. However, as the Bank rate has been consistently $0.5 \%$ since March 2009, to proxy the monetary environment, we used the 1-month London

\footnotetext{
10 To reemphasise the findings by Nasir and Soliman (2014) were based on the Frequentist approach and hence prone to the critique and Jeffery-Lindley's paradox. Nonetheless, their study focused on the Pre-GFC period where the financial landscape as well as the monetary policy framework and mandate was very different. Since, crisis there has been tremendous changes in the mandate of the Bank of England and its institutional design in the form of financial policy committee and responsibility of financial stability.
} 
Interbank Offered Rate, commonly called LIBOR. It's the rate of interest at which banks offer to lend money to one another in the wholesale money markets in the city of London. The LIBOR is watched closely by both professionals and private individuals because the LIBOR interest rate is used as a base rate (benchmark) by banks and other financial institutions. Concomitantly, the dynamics of LIBOR can have significant consequences for the interest rates on all sorts of banking products such as mortgages, savings accounts, and personal and business loans. Hence, in this way the LIBOR is a medium between the Bank rate and the real economy and in fact in practical sense more closer to the economy and financial sector (Upper 2012). ${ }^{11}$

In line with the practice in the Sect. (5.1), the analysis was started with the unit root, co-integration and lag selection test. The results of unit root test showed that all the series were stationary at first difference i.e. $I$ (1), although the fiscal policy variable (PSNB as $\%$ of GDP) was stationary even at the level $I(0)$. The lag selection showed six as optimal numbers of lags suggested by AIC, HQ, FPE and LR criteria. The SIC criteria showed 2 as optimal, however, we choose to go for 6 lags due to the fact that it was suggested by most of the criteria (Liew 2004). The Johansen method employed to test for the co-integration showed no sign it which implied that the statistical properties of the series were robust to the critique by Engle and Yoo (1987) as the data was not co-integrated. ${ }^{12}$ After testing the statistical properties of series to proceed to the estimation of our model using the Bayesian framework laid down in the Sect. (4.1). The results of the estimation are presented below in Table 5.

The Diagonal VAR was used for initial residual covariance in which the diagonal elements of the matrix are calculated from the full classical VAR (i.e. the diagonal elements are equal to those in the full VAR method, and the non-diagonal elements are set equal to zero). The hyper-parameters with the values cited in Table 5 were used. The value of $\mathrm{R}^{2}$ was quite high, coupled with high F-statistics in each case except for where the fiscal policy was the response variable, which is an indication of exogeneity in the fiscal policy operations, perhaps in the short-run. We observed a similar response of fiscal policy operations to other explanatory variables in the Pre-GFC period. However, the statistics were still reasonably high. The results incorporating six lags showed the various sign, size and significance for the values of the coefficient, concomitantly, to show an overall picture of the full analysis, an Impulse Response Function (IRF) analysis is performed and presented in Fig. 2.

The results of IRF analysis in the Post-GFC period showed that a shock to fiscal policy (expansionary operations) leads to increase in the yield of the bond (decrease in prices) which can be associated with the increase in the yield due to increased indebtedness of sovereign. Whereas, the shock to monetary policy (contractionary monetary operations) lead to the drop in the bond's yield (increase in the prices) which was contrary to findings by Tavares and Valkanov (2003) and Nasir and Soliman (2014). The shock to the stock market showed an increase in the yield (decrease in price) of the bonds which was more pronounced than the Pre-GFC period implying that in case of positive development in the stock markets in the Post-GFC period the bonds will have a rather more negative response. This general implication is a greater elasticity of substitution between the Bonds and stock markets in the Post-GFC period. This leads to the rejection of third null hypothesis of no impact of policies in the Post-GFC period $\left(H_{0}: b_{i}=0\right)$ which was rejected in favour alternative hypothesis of a none-zero impact $\left(H_{1}: b_{i} \neq 0\right)$.

11 (See Upper (2012) for detailed discussion which provides rationale to consider LIBOR to proxy monetary environment).

12 The results of Unit root, co-integration and lag selection are not presented here, however are available at request. 
Response to Cholesky One S.D. Innovations

Response of BONDS to FISCAL

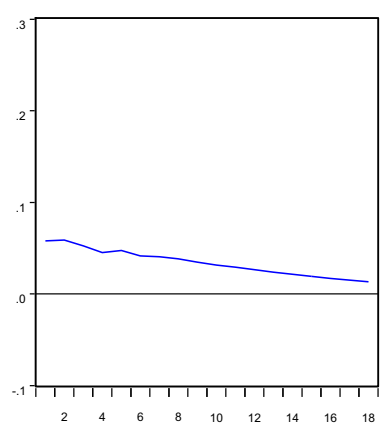

Response of BONDS to MONETARY

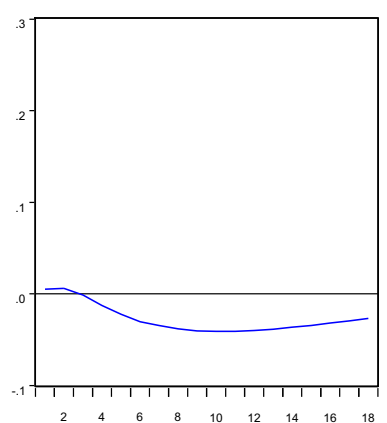

Response of BONDS to LNSTOCK

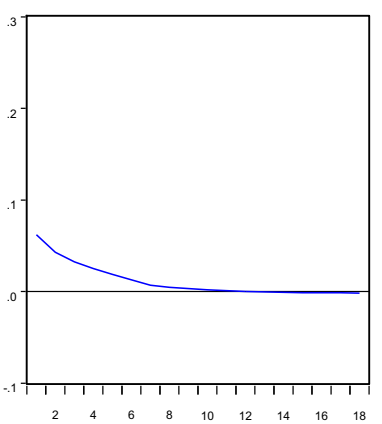

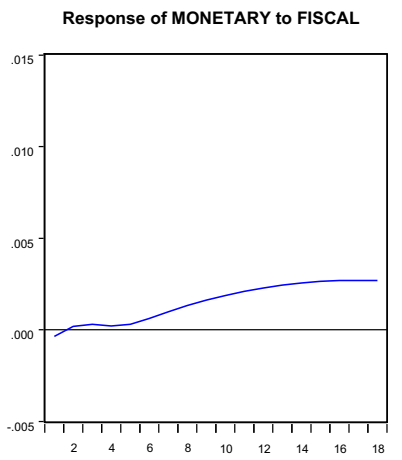

Response of FISCAL to MONETARY
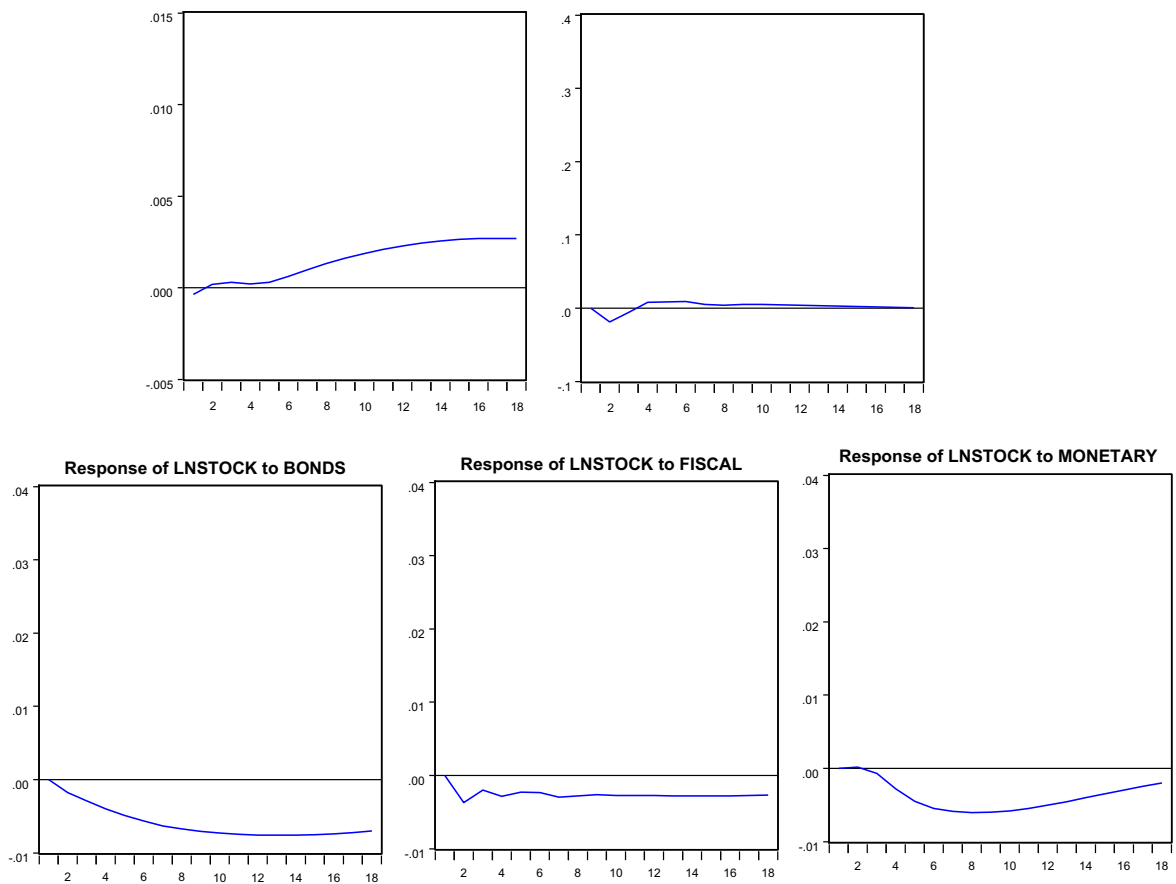

18

Fig. 2 Impulse response function (IRF): post global financial crisis. *There are no impulse response standard errors in Bayesian VAR model 
On the interaction of policies; the shock to the fiscal policy leads to increase in interest rate whereas the shock to monetary policy (contractionary operations) lead to the initial decrease in spending which later turned into an increase. The fourth null hypothesis of no interaction between policy or zero impact on each other $\left(H_{0}: b_{i}=0\right)$ was rejected in favour alternative hypothesis of interdependence or a non-zero impact $\left(H_{1}: b_{i} \neq 0\right)$ in a Bayesian Framework and Post-GFC period. At this point, we must emphasise that monetary policy for which we are using the LIBOR as a proxy due to the earlier cited reasons, is influenced by the stance of fiscal stance and vice versa in the Post-GFC period. However, the dynamics of interaction are different as the fiscal spending (expansionary operations) is leading to a wellpronounced and persistent contractionary monetary environment, which was not the case in the Pre-GFC world. One can associate it with the increase in the interest rates due to the Government borrowing crowding out the money market or the limitation of official instrument of monetary policy i.e. the Bank rate being close to the Zero Lower Bound (ZLB) and not able to influence short-term interest rates. However, there are a number of non-conventional measures which the Bank of England can use to influence this relationship e.g. purchase of Government and Corporate bonds and liquidity provision through different schemes. ${ }^{13}$ Obviously, to investigate it further, one can open separate lines of inquiry as it is beyond the scope of the subject study. On the interaction of financial markets, our IRF analysis showed that the response of the stock market to the increase in the yield of bonds was negative which also persisted for several periods, implying that the increase in the yield (drop in prices) of bonds negatively influence the stock market as well. The Stock market also showed a negative response to the shock to the fiscal policy (expansion) and monetary contraction. Concomitantly, in the Post-GFC period, the disciplined fiscal and accommodating monetary environment has been found to be optimal for the financial markets. It leads us to conclude.

\section{Conclusions and policy implications}

In light of the empirical findings and subsequent discussion, it can be hereby concluded that the arguments for macroeconomic policy interaction, interdependence and coordinated operations made by earlier studies (most focusing the real economy and less frequently on the financial sector) stands. This study verified the notion of policy coordination against the Jeffreys-Lindley's paradox which gives us further insight into the underlying relationship among policy operations, aspect of policy coordination and financial sector dynamics. It is worth reiterating one more point from our earlier cited findings, that, in the long term, the financial (Stock and Bonds) markets and macroeconomic policies are found to be interdependent and that the dynamics of the markets are influenced by each other as well as policy interactions. On the aspect of the implication of Global Financial Crises (2008), it can be

13 An example of that is the Special Liquidity Scheme and Funding for Lending scheme launched by the Bank of England. More recently the Bank of England, added more Corporate and Government Bonds on its balance sheet and launching Term Funding Scheme, for details please see http://www.bankofengland.co.uk/ publications/Pages/news/2016/063.aspx. It is worth acknowledging that the most frequently used measure of the monetary policy is the policy rates. The unconventional measures are taken in the extreme situation. We are not directly assessing the impact of QEs as they are a separate subject on which there are some studies on Q.Es and real economy (see Haldane 2015) for details or financial/capital flows (see e.g. Lim and McNelis (2018). Nonetheless the studies which have focused on the QE have reported that it leads to easing of credit conditions (See, Joyce et al. 2014; Haldane 2015; Nasir 2017). However, there are also concerns that it is not a permanent solution and therefore can bot be used as a permanent tool for policy operations (All seasons Q.E as Haldane 2015 put it). For all these reasons, the aspect of Q.E is a little of the road, however, in the future studies on Q.Es other researcher may explore this path. 
concluded that the policy interaction and coordinated operations are still vital, though there have been profound changes in the institutional design of Bank of England and its mandate. The responsiveness of the stock and bond markets have been increased which can be associated with the increase in the elasticity of substitution or an increase in the sensitivity of the investor's portfolio adjustment in the Post-GFC world. In our closing lines, we argue that one of the positive aspects of Jeffreys-Lindley's paradox and theoretical implication of our study is the possibility of employing them as alternative empirical frameworks and techniques that are considered as complementary rather than competing. Perhaps there does situations as the subject prevails where both Frequentist and Bayesian approaches complement each other, thus, it implies that if we are occasioned with the contrasting results, it may require further exploration for the contrast. In specific to the subject case, such a contrast does not hold. This also has profound practical and operational implications and the policymakers and researchers can base their judgment on both approaches for a deeper insight into the impact of policies. Hence, we argue that it is not always necessarily the case that the estimation and choice of empirical framework produce contradictory findings and lead to conflicting conclusions. Rather, they may complement each other or as we found in the study that both frameworks complemented each other's claims by providing further insight, where one of the two was not fully capable of doing so and also when the results were not conclusive. Nevertheless, policy coordination and coordinated policy operations are still valid even in the Post-GFC world. The scope of the subject study is limited to analysing the implications of Jeffery-Lindley's paradox and Global Financial Crisis for the operational aspect of macroeconomic policy coordination and financial stability while focusing on the UK stock and bonds markets. However, for future research, analysis can be extended to other aspects of financial markets, for instance, the Forex markets, other developed and developing economies, countries which are in the monetary union or have different exchange rate regimes and monetary authorities' institutional framework. The analysis can also be extended to other industries where the operational managers and policymakers employ various analytical techniques in the areas of Management, Economics and Finance.

Open Access This article is licensed under a Creative Commons Attribution 4.0 International License, which permits use, sharing, adaptation, distribution and reproduction in any medium or format, as long as you give appropriate credit to the original author(s) and the source, provide a link to the Creative Commons licence, and indicate if changes were made. The images or other third party material in this article are included in the article's Creative Commons licence, unless indicated otherwise in a credit line to the material. If material is not included in the article's Creative Commons licence and your intended use is not permitted by statutory regulation or exceeds the permitted use, you will need to obtain permission directly from the copyright holder. To view a copy of this licence, visit http://creativecommons.org/licenses/by/4.0/.

\section{References}

Aarle, B. V., Engwerda, J., \& Plasmans, J. (2002). Monetary and fiscal policy interaction in the EMU: A dynamic game approach. Annals of Operations Research, 109(1-4), 229-264.

Airaudo, M., Cardani, R., \& Lansing, K. J. (2011). Monetary policy and asset prices with belief-driven fluctuations and news shocks. Philadelphia: LeBow College of Business, Drexel University.

Andrew, H. H., Libich, J., \& Stehlik, P. (2011). Welfare improving coordination of fiscal and monetary policy. AUCO Czech Economic Review, 5, 7-26.

Ardagna, S. (2009). Financial markets behaviour around episodes of large changes in the fiscal stance. European Economic Review, 53, 37-55.

Arnold, I. J. M., \& Vrugt, E. B. (2010). Treasury bond volatility and uncertainty about monetary policy. The Financial Review, 45, 707-728. 
Banbura, T., Giannone, R., \& Reichlin, C. (2010). Large Bayesian vector auto regressions. Journal of Applied Econometrics, 25(1), 71-92.

Berger, A. N., \& Bouwman, C. H. S. (2012). Bank liquidity creation, monetary policy, and financial crises. Available at SSRN: http://ssrn.com/abstract=1952728.

Bredin, D., Hyde, S., Nitzsche, D., \& O'reilly, G. (2007). UK stock returns and the impact of domestic monetary policy shocks. Journal of Business Finance and Accounting, 34, 872-888.

Broome, S., \& Morley, B. (2004). Stock prices as a leading indicator of the East Asian financial crisis. Journal of Asian Economics, 15, 189-197.

Campbell, J. Y. (1995). Some lessons from yield curve. Journal of Economic Perspectives, 9(3), 129-152.

Canova, F. (2007). Methods for applied macroeconomic research. Princeton, NJ: Princeton University Press.

Carroll, C. D., Otsuka, M., \& Slacalek, J. (2011). How large are housing and financial wealth effects? A new approach. Journal of Money, Credit, and Banking, 43, 55-79.

Davig, T., \& Leeper, E. M. (2011). Monetary-fiscal policy interactions and fiscal stimulus. European Economic Review, 55, 211-227.

Dixit, A., \& Lambertini, L. (2001). Monetary-fiscal policy interactions and commitment versus discretion in a monetary union. European Economic Review, 45, 977-987.

Dixit, A., \& Lambertini, L. (2003). Symbiosis of monetary and fiscal policies in a monetary union. Journal of International Economics, 60, 235-247.

Doan, T., Litterman, R., \& Sims, C. (1984). Forecasting and conditional projection using realistic prior distributions, Econometric Reviews, 3(1), 1-100.

Dosi, G., Minenna, M., Roventini, A., \& Violi, R. (2019). Making the Eurozone work: A risk-sharing reform of the European stability mechanism. Annals of Operations Research. https://doi.org/10.1007/s10479-0 19-03325-9.

Engle, R. F., \& Yoo, B. S. (1987). Forecasting and testing in co-integrated systems. Journal of Econometrics, 35(1), 143-159.

Fanchon, P., \& Wendel, J. (1992). Estimating VAR models under non-stationarity and cointegration: Alternative approaches for forecasting cattle prices. Applied Economics, 24(2), 207-217.

Fischbacher, U., Hens, T., \& Zeisberger, S. (2012). The impact of monetary policy on stock market bubbles and trading behavior: Evidence from the Lab. Journal of Economic Dynamics and Control, 37, 2104-2122.

Flotho, S. (2018). Interaction of fiscal and monetary policy in a monetary union under the zero lower bound constraint. Annals of Operations Research, 260(1-2), 159-196.

Funke, M., Paetz, M., \& Pytlarczyk, E. (2010). Stock market wealth effects in an estimated DSGE model for Hong Kong. Economic Modelling, 28, 316-334.

Gulley, O. D., \& Sultan, J. (2003). The link between monetary policy and stock and bond markets: Evidence from the federal funds futures contract. Applied Financial Economics, 13, 199-209.

Haldane, A. G. (2015). How low can you go? Speech given at the Portadown Chamber of Commerce, Northern Ireland. Retrieved January 1, 2017 from http://www.bankofengland.co.uk/publications/Pages/speeches/ 2015/840.aspx.

Hautsch, N., Kyj, L. M., \& Malec, P. (2011). The merit of high-frequency data in portfolio allocation. SFB 649, Discussion papers 2011-059.

Jansen, D. W., Li, Q., Wang, Z., \& Yang, J. (2008). Fiscal policy and asset markets: A semi-parametric analysis. Journal of Econometrics, 147, 141-150.

Jeffreys, H. (1939). Theory of probability (1st ed.). Oxford: The Clarendon Press.

Joyce, M., Liu, Z., \& Tong, M. (2014). Institutional investor portfolio allocation, quantitative easing and the global financial crisis. Bank of Working Paper No. 510.

Kontonikas, A., MacDonald, R., \& Saggu, A. (2013). Stock market reaction to fed funds rate surprises: State dependence and the financial crisis. Journal of Banking \& Finance, 37(11), 4025-4037.

Koop, G., \& Korobilis, D. (2010). Bayesian multivariate time series methods for empirical macroeconomics. Foundations and Trends in Econometrics, 3(4), 267-358.

Leeper, E. (1993). The Policy Tango; towards a holistic view of monetary and fiscal effects. Economic Review, Federal Reserve Bank of Atlanta, 78, 1-27.

Liew, V. K-S. (2004). Which lag length selection criteria should we employ? Economics Bulletin, 3(33), 1-9.

Lim, G. C., \& McNelis, P. D. (2018). Unconventional monetary and fiscal policies in interconnected economies: Do policy rules matter? Journal of Economic Dynamics \& Control, 93, 346-363.

Lindley, D. V. (1957). A statistical paradox. Biometrika, 44(1-2), 187-192.

Litterman, R. (1984). Specifying VAR's for macroeconomic forecasting. Federal Reserve Bank of Minneapolis Staff report no. 92 .

MacKinnon, J. G., Haug, A. A., \& Michelis, L. (1999). Numerical distribution functions of likelihood ratio tests for cointegration. Journal of Applied Econometrics, 14, 563-577. 
Malikane, C., \& Semmler, W. (2008). Asset prices, output and monetary policy in a small open economy. Metroeconomica, 59, 666-686.

Merola, R. (2009). A Bayesian estimation of a DSGE model with financial frictions, Research paper series, 7, 149-September.

Milani, F., \& Poirier, D. J. (2007). Econometric issues in DSGE models. Econometric Reviews, 26, $201-204$.

Muscatelli, A., Tirellil, P., \& Trecroci, C. (2004). Fiscal and monetary policy interactions: Empirical evidence and optimal policy using a structural New-Keynesian model. Journal of Macroeconomics, 26, 257-280.

Naaman, M. (2016). Almost sure hypothesis testing and a resolution of the Jeffreys-Lindley paradox. Electronic Journal of Statistics, 10(1), 1526-1550.

Nasir, M. A. (2017). Zero lower bound \& negative interest rates: Choices for the monetary policy. Retrieved February 3, 2017 from https://ssrn.com/abstract=2881926 or http://dx.doi.org/10.2139/ssrn.2881926.

Nasir, M. A., Ahmad, M., Ahmad, F., \& Wu, J. (2015). Financial and economic stability as 'two sides of a coin': Non-crisis regime evidence from the UK based on VECM. Journal of Financial Economic Policy, 7, 327-353.

Nasir, M. A., \& Du, M. (2018). Integration of financial markets in post global financial crises and implications for British financial sector: Analysis based on a panel VAR model. Journal of Quantitative Economics, 16(2), 363-388.

Nasir, M. A., \& Soliman, A. M. (2014). Aspect of policy combination \& effects on financial markets. Economic Issues, 19, 92-118.

Neck, R. (1999). Dynamic games of fiscal and monetary policies for Austria. Annals of Operations Research, $88,233-249$.

Neck, R., \& Karbuz, S. (1995). Optimal budgetary and monetary policies under uncertainty: A stochastic control approach. Annals of Operations Research, 58(5), 379-402.

Paulson, J. W. (2013). Facing the portfolio allocation decision, economic \& market perspective update. San Francisco: Wells Capital Management.

Pecican, E. S. (2010). Forecasting based on open VAR model. Romanian Journal of Economic Forecasting, Institute of Economic Forecasting, 13, 59-69.

Pindyck, R. S., \& Rubinfeld, D. L. (1997). Econometric models and econometric forecasts. New York: Irwin McGraw Hill.

Politis, D. N., Romano, J. P., \& Wolf, M. (1999). Sub-sampling, Springer series in statistics. Berlin: Springer.

Porqueras, P. G., \& Alva, A. P. (2010). Optimal monetary and fiscal policies in a search theoretic model of monetary exchange. European Economic Review, 54, 331-344.

Robert, C. P. (2013). On the Jeffrey's-Lindley's paradox. Paris: Université Paris-Dauphine, CEREMADE, University of Warwick, Department of Statistics, and CREST.

Sargent, T. S., \& Wallace, N. (1981). Some unpleasant monetarist arithmetic. Minneapolis: Research Department, Federal Reserve Bank of Minneapolis.

Saulo, H., Rêgo, L. C., \& Divino, J. A. (2013). Fiscal and monetary policy interactions: A game theory approach. Annals of Operations Research, 206(1), 341-366.

Sims, C. A. (2011a). Models and their uses. American Journal of Agricultural Economics, 71(2), 489-494.

Sims, C. A. (2011b). Stepping on a rake: The role of fiscal policy in the inflation of the 1970s. European Economic Review, 55, 48-56.

Sims, C., Stock, J., \& Watson, M. (1990). Inference in linear time series models with some unit roots. Econometrica, 58(1), 113-144.

Spanos, A. (2013). Who should be afraid of the Jeffreys-Lindley paradox? Philosophy of Science, 80(1), 73-93.

Sprenger, J. (2013). Testing a precise null hypothesis: The case of Lindley's paradox. Philosophy of Science, $80,733-744$.

Tavares, J., \& Valkanov, R. (2003). The neglected effect of fiscal policy on stock and bond returns. In EFA 2003 annual conference paper No. 201.

Upper, C. (2012). The importance of reference rates. BIS Quarterly Review 21-22. https://www.bis.org/publ/ qtrpdf/r_qt1212w.htm.

Villa, C., \& Walker, S. (2017). On the mathematics of the Jeffreys-Lindley paradox. Communications in Statistics-Theory and Methods, 46, 12290-12298.

Wang, S., \& Mayes, D. G. (2012). Monetary policy announcements and stock reactions: An international comparison. The North American Journal of Economics and Finance, 23, 145-164.

Wong, W. K., Khan, H., \& Du, K. J. (2006). Do the interest rates matter for stock prices? An economic study of Singapore \& U.S.A. The Singapore Economic Review, 51, 31-51.

Wrane, A. (2006). Bayesian inference in cointegrated VAR model with applications to the demand for Euro Area M3. European Central Bank, Working paper series no 692/November. 
Zubairy, S. (2009). On fiscal multipliers: Estimates from a medium scale DSGE model. Bank of Canada, and Bank of Canada Working paper 2010-30.

Publisher's Note Springer Nature remains neutral with regard to jurisdictional claims in published maps and institutional affiliations. 